\title{
Effects of grazing cow diet on volatile compounds as well as physicochemical and sensory characteristics of 12-month-ripened Montasio cheese
}

\author{
E. Aprea ${ }^{* 1}$ A. Romanzin, $†$ M. Corazzin, $\dagger$ S. Favotto, $†$ E. Betta, ${ }^{*}$ F. Gasperi, ${ }^{*}$ and S. Bovolenta† \\ *Department of Food Quality and Nutrition, Research and Innovation Centre, Fondazione Edmund Mach (FEM), Via E. Mach, 1, \\ 38010 San Michele all'Adige, Italy \\ †Department of Agriculture, Food, Environmental and Animal Sciences, University of Udine, Via delle Scienze 206, 33100 Udine, Italy
}

\begin{abstract}
The aim of this study was to evaluate the effects of pasture type and cow feeding supplementation level on a 12-mo-ripened Montasio protected designation of origin (PDO) cheese, which is one of the most important PDO cheeses produced in northeast Italy. Cheeses were characterized for volatile compounds, color, mechanical variables, and sensory descriptors. Pasture type significantly affected most of the instrumental variables considered and, as a consequence, sensory properties were affected as well. Cheeses from the pasture characterized by a nutrient-rich vegetation type were higher in protein and lower in fat content. Furthermore, such cheeses, evaluated by a sensory panel, were more intense in color with a more pungent and less cow-like odor, in agreement with what found through instrumental analyses. Supplementation level resulted in less pronounced effects, limited to volatile compounds and texture properties, which were not detected by sensory analysis. The characterization of the 12-mo ripened Montasio cheese reported here is an important step for the valorization of this PDO product.
\end{abstract}

Key words: pasture type, supplement level, ripened cheese, volatile organic compound, sensory property

\section{INTRODUCTION}

Cheese quality depends on chemical, rheological, and microbiological characteristics of the milk, which are affected by, among other factors, the cow's diet (Coulon et al., 2004; Martin et al., 2005). In grazing cows, which are mainly widespread in mountain areas in Italy, the characteristics of the diet depend on the type of pasture

Received January 21, 2016.

Accepted April 25, 2016.

${ }^{1}$ Corresponding author: eugenio.aprea@fmach.it (i.e., productivity, floral composition, herbage maturity) as well as feeding supplementation (i.e., quantity, quality, pattern of distribution).

The different floral compositions of alpine pastures affect cheese quality by means of transferring volatile organic compounds (VOC) from the grass to the milk and finally to the cheese (Noni and Battelli, 2008; Revello Chion et al., 2010), or, with regard to color, providing different carotenes (Noziere et al., 2006). However, the botanical composition of different grasses can also have indirect effects, mediated by the proteolytic enzymes present in milk. Buchin et al. (1999), for example, ascribed sensory differences of cheeses made from the milk of cows grazing in different types of pastures to the presence of specific toxic plants (e.g., Ranunculus) able to increase the concentration of plasmin in milk. In relation to cheese made from raw milk (not pasteurized), a different microbial contamination resulting from different floristic composition of the pastures or during grazing period may occur (Hagi et al., 2010; Montel et al., 2014).

Less investigated are the effects of feeding supplementation on cheese quality; however, many studies show its effects on milk composition and on the rheological characteristics. In fact, the supplements may modify the quantity and quality of herbage intake (Bovolenta et al., 2005, 2008) and the metabolic pathways that, starting from the rumen, lead to the formation of VOC in milk (Jenkins and McGuire, 2006).

During ripening, VOC production depends on the effect of fermentation of lactose not lost in the whey, proteolysis, and lipolysis. In particular, proteolysis of caseins results in the production of small- and mediumsized peptides of and free AA. These are important precursors of different volatile compounds, such as amines, aldehydes, alcohols, acids, phenols, and sulfur compounds. The lipolysis implies the release of shortand medium-chain fatty acids. Free fatty acids can be further metabolized to produce methyl-ketones, secondary alcohols, lactones, and esters (McSweeney, 2004). 
The quantity of VOC and the sensory quality of cheese are often not closely related. The compounds with low detection thresholds are, in many cases, those that contribute most to sensory attributes (Curioni and Bosset, 2002). In addition, different compounds affect the relationship between the concentration and perceived intensity (Thomsen et al., 2012). Sensory sciences provide standardized methods to determine the product characteristics perceived by human senses and to study consumer behavior (Drake, 2007).

The link between cow diet and cheese quality is essential for Protected Designation of Origin (PDO) cheeses because it is the basis of the terroir concept, defined by French researchers to identify a production system based on peculiar environmental conditions, animal ability to exploit local resources, and sustainable agricultural practices (Barham, 2003). Montasio, a semihard and semicooked cheese, is one of the most important PDO cheeses produced in northeast Italy. The production area of this cheese includes mountains (Montasio takes its name from a mountain plateau), but also the plain (Romanzin et al., 2013). During the summer, farmers maintain their cows grazing on highaltitude pastures. In this context, Montasio made from the milk of grazing cows is sold on site the same year of production (with a minimum ripening of $2 \mathrm{mo}$ ) or the following summer season (12 mo or more). Therefore, for the producers it is important to assess the effects of feeding management of grazing animals on fresh cheese and on 12-mo ripened cheese.

In a previous paper (Bovolenta et al., 2014), we focused on fresh Montasio PDO cheese with 2 mo of ripening. In this study, our aim was to analyze the volatile compounds as well as physicochemical and sensory characteristics of 12-mo-ripened cheeses produced from the milk of Italian Simmental cows grazing on different alpine pastures and receiving different levels of concentrate supplementation.

\section{MATERIALS AND METHODS}

\section{Experimental Design and Treatments}

The experiment was carried out in a summer alpine farm (Malga Montasio, Udine, Italy; $46^{\circ} 24^{\prime} 45^{\prime \prime} \mathrm{N}$, $13^{\circ} 25^{\prime} 53^{\prime \prime} \mathrm{E}$; altitude $\left.=1,500-1,800 \mathrm{~m}\right)$. Two pastures with different vegetation types (nutrient-rich or nutrient-poor) were grazed at the same phenological stage by 72 Italian Simmental cows. During the 10-d experimental period, 36 cows (high group) were supplemented with $3 \mathrm{~kg}$ /head per day, on average, of a commercial mixed concentrate. The other 36 cows (low group) were supplemented with $1.5 \mathrm{~kg} /$ head per day, on average, of the same concentrate. More details on the experimental design, animal performances, pasture types, and diet characteristics have already been described in Bovolenta et al. (2014).

\section{Cheese Manufacture}

The experimental cheeses were produced from whole and raw milk from 2 consecutive milkings. Cheesemaking was repeated for the last 3 consecutive days of the experimental period for each experimental group (12 cheesemaking sessions) in accordance with the product specification of PDO Montasio, as reported in Bovolenta et al. (2014). Cheeses were ripened for $12 \mathrm{mo}$ in a cellar with controlled temperature $\left(12^{\circ} \mathrm{C}\right)$ and humidity (85\%) until sampled for analysis.

\section{Chemical and Physical Analysis}

Cheese samples were analyzed for DM, fat, total N, and soluble $\mathrm{N}$ at $\mathrm{pH} 4.6$ according to the AOAC International (2000) methods. Protein content was obtained by multiplying total $\mathrm{N} \times 6.38$. The ripening index was calculated as ratio $(\times 100)$ between soluble and total $\mathrm{N}$. The color of the cheese paste was measured with a chroma-meter (CR 400, Minolta, Osaka, Japan) and expressed as lightness $\left(\mathrm{L}^{*}\right)$, redness $\left(\mathrm{a}^{*}\right)$, and yellowness ( $b^{*}$ ) using the CIE standard illuminant D65.

The rheological properties of cheeses were evaluated with a texture analyzer (TA Plus, Lloyd Instruments, Sussex, UK) using the procedure described by Gunasekaran and Ak (2003). The rheological variables considered were hardness, cohesiveness, adhesiveness, springiness, gumminess, and chewiness.

\section{Volatile Compound Profiling by Solid Phase Microextraction GC-MS}

Volatile compounds in the headspace of the cheese samples were analyzed according solid phase microextraction GC-MS technique following the same procedure and the same instruments used and described in Bovolenta et al. (2014). Each sample was prepared and analyzed in triplicate. Results are reported as milligrams per kilogram equivalent to the internal standard (ethyl heptanoate for the esters; isobutanoic acid for the carboxylic acids; 4-methyl-2-pentanone for all the other compounds). The 3 standards were chosen to partially compensate for the different fiber compound responses. 
Table 1. List of sensory attributes developed and used by the expert panel to evaluate the ripened Montasio cheese

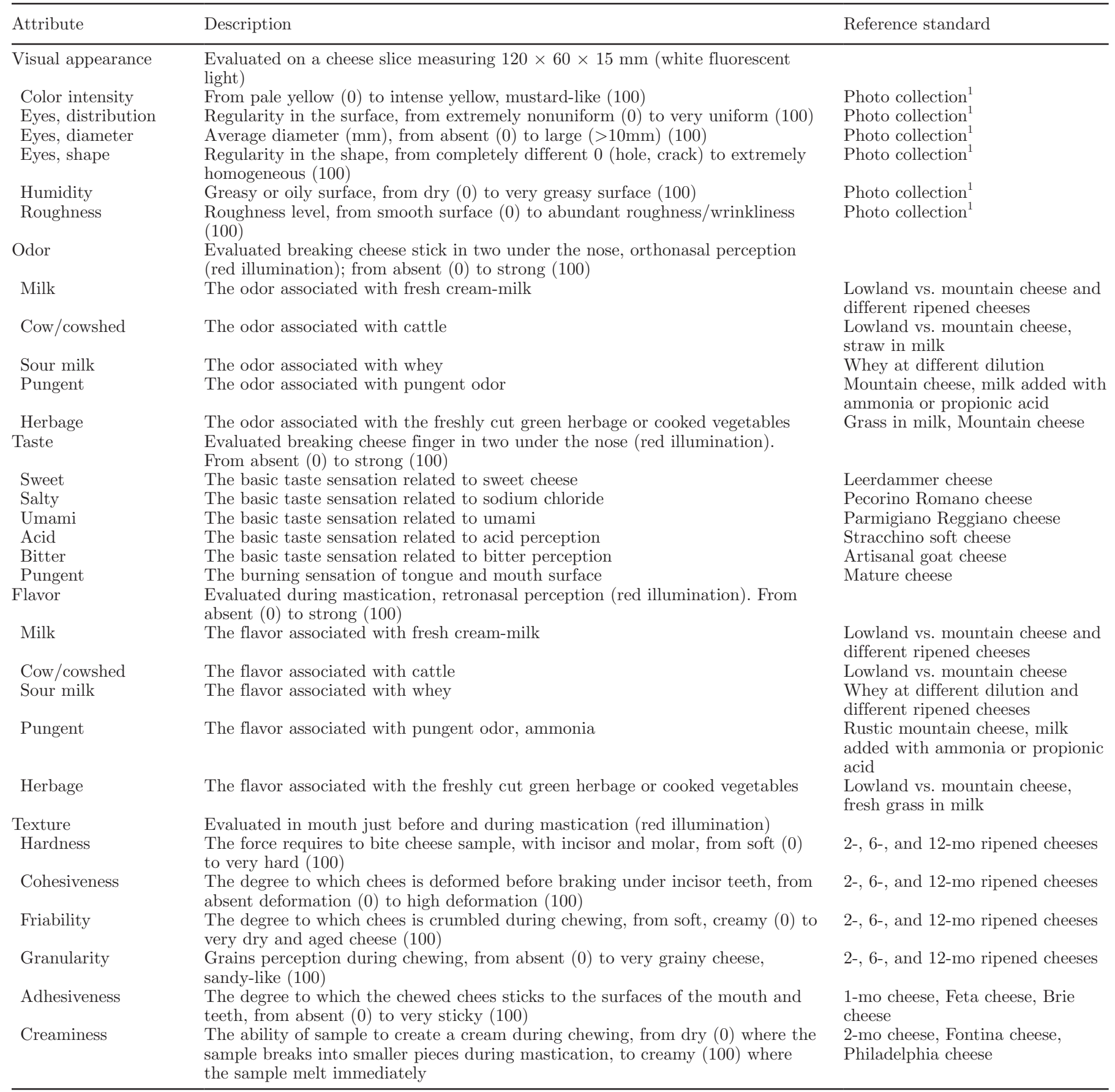

${ }^{1}$ Supplementary Figure S1 (http://dx.doi.org/10.3168/jds.2016-10929).

\section{Descriptive Sensory Analysis}

The quantitative descriptive analysis (Meilgaard et al., 2007) on Montasio cheese was performed by a panel of 12 trained assessors with previous experience on cheese sensory evaluation. During preliminary sessions, the assessors developed and then agreed on a consensus list of 28 attributes suitable for 12-mo ripened cheeses (Table 1).

During sensory test, each judge evaluated, in 3 successive sessions, 6 cheeses from rich pastures (3 cheesemakings for each of the 2 supplement levels from the 
Table 2. Chemical composition, ripening index, and physical properties of cheeses

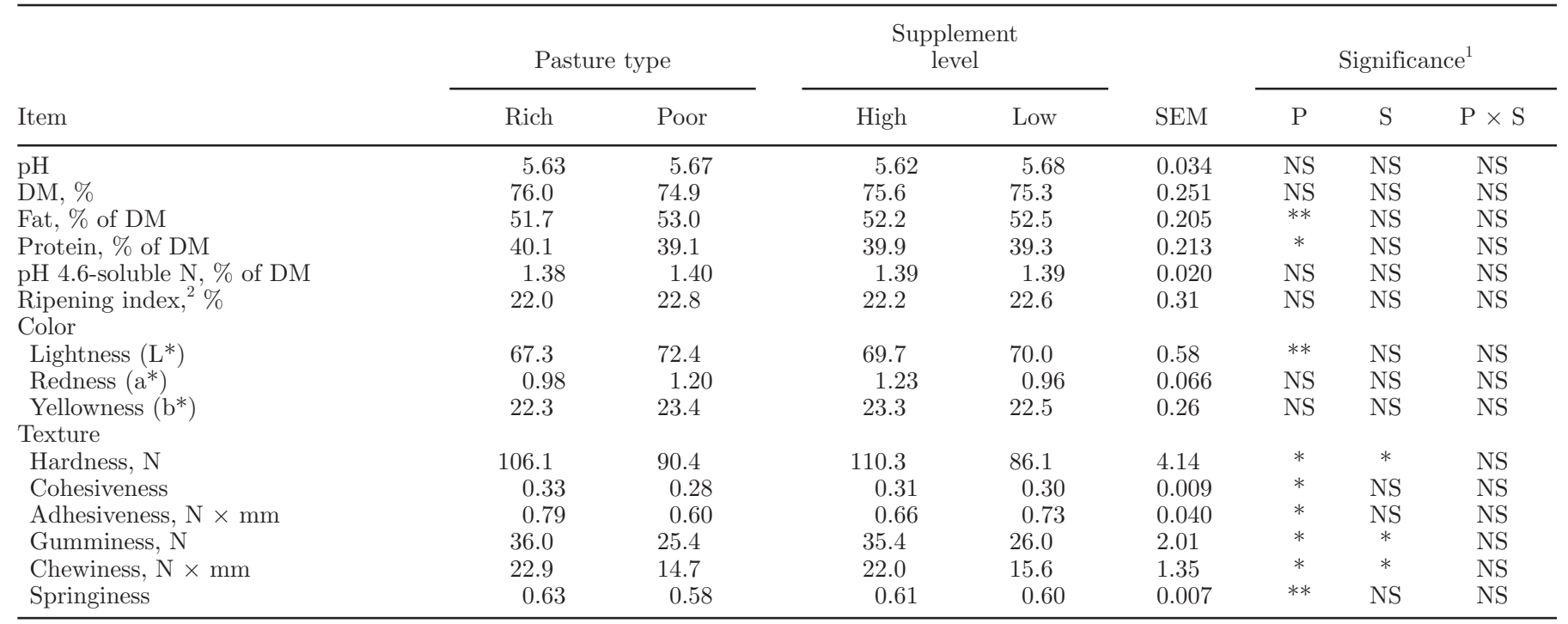

${ }^{1} \mathrm{P}=$ pasture type; $\mathrm{S}=$ supplement level; $\mathrm{P} \times \mathrm{S}:=$ interaction between the factors.

${ }^{* *} P<0.01 ;{ }^{*} P<0.05 ; \mathrm{NS}=P>0.05$.

rich pasture thesis) and, in an additional 3 successive sessions, the other 6 cheeses (from the poor pasture thesis). Sensory analysis was performed in a laboratory, at University of Udine (Udine, Italy), built according to the UNI EN ISO (UNI, 2010) standard. Assessors gave an intensity score on a 100-mm unstructured scale, anchored at each end.

\section{Statistical Analysis}

The statistical analysis was performed using SPSS 7.5.21 (SPSS Inc., Chicago, IL) or Statistica 9.1 (StatSoft, Tulsa, OK). Normality of data distribution and homogeneity of variance were tested using KolmogorovSmirnoff and Levene test, respectively. Cheese composition, color variables, rheological proprieties, and volatile compounds data were subjected to 2-way ANOVA with pasture type (rich, poor) and supplement level (high, low) treated as fixed factors. Interaction between pasture type and supplement level was calculated as well. Sensory data were analyzed using mixed model where supplement level and pasture type were considered as fixed effects, and judge as random effect. Differences were considered significant at $P<0.05$, taking into account correction for multiple comparisons (Dunn, 1961). Volatile compounds data were also processed by principal component analysis (PCA) carried out using SIMCA-P+12.0 (Umetrics, Umea, Sweden). Data were mean centered and variables were weighted with 1/ standard deviation and the full cross-validation method (leave one out) was used.

\section{RESULTS AND DISCUSSION}

\section{Chemical Composition and Physical Proprieties}

Chemical composition of the experimental cheeses (Table 2) was significantly affected by the pasture type; fat $(P<0.01)$ was higher in poor pasture cheeses whereas protein $(P<0.05)$ was higher in rich pasture cheeses. On the contrary, supplement level did not affect chemical composition, confirming the results obtained on the same cheeses at 2 mo of ripening. The differences of the energy intake in this experiment were probably not so high as to influence the chemical composition and, in particular, the protein content. An increase in the energy level of the diet often leads to an increase in protein and a decrease in milk fat, and this condition is maintained in the cheese (Bovolenta et al., 2009).

The semicooked and pressed cheeses, such as Montasio, generally have a rather limited proteolysis compared with other types of cheeses, even in cases of long ripening (Salvadori del Prato, 2001). Cheeses had a mean ripening index of $22.4 \%$, not different between the experimental factors.

Regarding color variables, lightness index of 12-mo cheeses was markedly reduced compared with same fresh cheeses (Bovolenta et al., 2014) and was affected by pasture type $(P<0.01)$. Marchesini, et al., (2009), in a study of Asiago cheese, highlighted a linear decrease of lightness $\left(\mathrm{L}^{*}\right)$ through the aging time. Furthermore, those authors found a negative correlation with the protein level that may explain why the cheese produced on poor pasture was lighter than rich pasture 
Table 3. Volatile compounds $(\mathrm{mg} / \mathrm{kg})$ identified in the headspace of cheeses by solid-phase microextraction GC-MS analysis

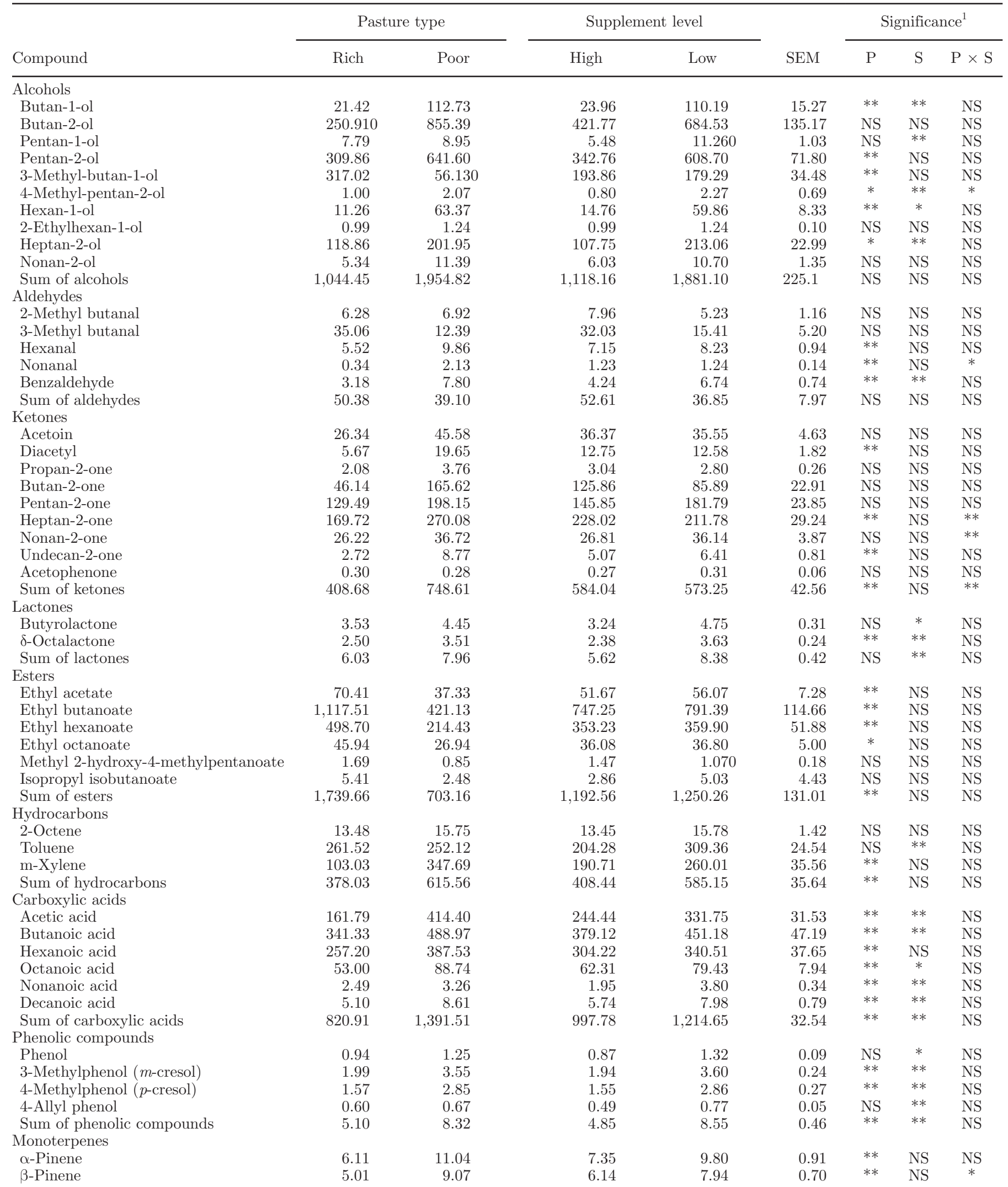


Table 3 (Continued). Volatile compounds $(\mathrm{mg} / \mathrm{kg})$ identified in the headspace of cheeses by solid-phase microextraction GC-MS analysis

\begin{tabular}{|c|c|c|c|c|c|c|c|c|}
\hline Compound & \multicolumn{2}{|c|}{ Pasture type } & \multicolumn{2}{|c|}{ Supplement level } & SEM & \multicolumn{3}{|c|}{ Significance $^{1}$} \\
\hline $\begin{array}{l}\beta \text {-Citronellene } \\
\text { (3,7-Dimethyl-1,6-octadiene) }\end{array}$ & 6.05 & 12.98 & 8.09 & 10.95 & 1.34 & $*$ & NS & NS \\
\hline Camphene & 0.69 & 2.46 & 1.45 & 1.69 & 0.20 & ** & NS & NS \\
\hline Limonene & 5.69 & 9.56 & 6.75 & 8.50 & 0.92 & $*$ & NS & NS \\
\hline Sabinene & 1.59 & 2.04 & 1.78 & 1.85 & 0.18 & NS & NS & NS \\
\hline $\begin{array}{l}\text { Sulfur compounds } \\
\text { Carbon disulfide }\end{array}$ & 3.58 & 0.73 & 2.41 & 191 & 027 & $* *$ & NS & NS \\
\hline Dimethyl sulfide & $\begin{array}{l}5.00 \\
9.60\end{array}$ & 13.27 & $\begin{array}{l}2.41 \\
9.97\end{array}$ & $\begin{array}{r}1.91 \\
12.89\end{array}$ & $\begin{array}{l}0.27 \\
1.23\end{array}$ & $* *$ & * & $\begin{array}{ll}\mathrm{NS} \\
\mathrm{NS}\end{array}$ \\
\hline Dimethyl sulfone & 4.16 & 5.05 & 3.81 & 5.40 & $\begin{array}{l}1.20 \\
0.40\end{array}$ & NS & $* *$ & NS \\
\hline Methanthiol & 1.79 & 3.38 & 2.16 & 3.01 & 0.41 & NS & NS & NS \\
\hline Sum of sulfur compounds & 19.13 & 22.43 & 18.35 & 23.21 & 1.29 & NS & NS & NS \\
\hline
\end{tabular}

${ }^{1} \mathrm{P}=$ pasture type; $\mathrm{S}=$ supplement level; $\mathrm{P} \times \mathrm{S}=$ interaction between the factors.

${ }^{*} * P<0.01 ; * P<0.05 ; \mathrm{NS}=P>0.05$.

$(P<0.01)$. Other color variables were not affected by the experimental factors.

Several texture variables were different among the evaluated cheeses. In particular, rich-pasture and highsupplement-level cheeses were harder, gummier, and chewier. Moreover, rich-pasture cheeses were more cohesive, adhesive, and chewable than poor-pasture cheese. The effect of pasture type can be attributed partly to differences in chemical composition and partly to the variability of holes characteristics between cheeses (see Sensory Panel Evaluation section). It is more difficult to explain the differences between the 2 levels of integration, considering that both the data of the chemical composition and the results of the sensory analysis (see the paragraph on sensory panel evaluation) are not different. Interaction between the 2 factors (pasture, supplement level) did not reach a significant level for any of the chemical or physical variables in Table 2 .

\section{Volatile Compounds}

After 12 mo of ripening, we identified 56 volatile compounds in the headspace of Montasio cheese (Table 3), whereas at 2 mo of ripening we found 61 volatile compounds (as reported in Bovolenta et al., 2014). Acetaldehyde, diethyl methylamine, heptan3-one, 1,8-cineol, 2-phenyl-2-propanol, and a terpene, tentatively identified as (E)-8-hydroxylinalool, were not found after 12 mo of ripening. The analysis of ripened cheeses allowed the identification of an additional terpene, namely $\beta$-citronellene. This latter compound was also present at trace levels in the 2-mo ripened cheeses, but was not previously identified for the low signal and consequent poor MS spectra quality.
Figure 1 reports the PCA of the cheese samples at 2 and 12 mo of ripening, accounting for $70 \%$ of explained variance. The PCA was based on the 56 volatile compounds in common between the 2 data sets $(2$ and 12 mo of ripening). As expected, the main difference in the cheese samples is due to the maturation; indeed, samples are clearly separated along the first component, explaining $63 \%$ of the observed variance. Furthermore, variability between the samples increases with ripening (data-points are more scattered) and differences related to pasture type are more evident in ripened cheeses compared with the young ones (second component).

Focusing on mature cheeses, Figure 2 reports the first 3 PCA scores, accounting for $74 \%$ of sample variability. It is possible to highlight both the effect of pasture type along first and second component, and supplement level along first and third component, on volatile profiling. Going more into detail, the ANOVA indicates that 33 and 19 volatile compounds are statistically different between the cheeses for pasture type and supplement level, respectively, and the interaction between pasture and supplement is statistically significant for 5 volatile compounds (Table 3). Both experimental factors (pasture and supplement) influence the lipolysis $(P<$ $0.01)$, causing an increase of free fatty acids in cheeses prepared with milk from cows grazed on poor pasture or fed with low levels of supplement, as reported in Figure $3 \mathrm{a}$, where the boxplots of the sum of the VFA are represented. The further transformation of free fatty acids in ethyl esters is influenced by pasture type $(P<$ 0.01 ), as esters are more abundant in cheese prepared with milk from cows grazed on rich pasture (Figure $3 \mathrm{~b}$ ). Furthermore, the amount of esters in mature cheeses is not influenced by level of supplement provided to 


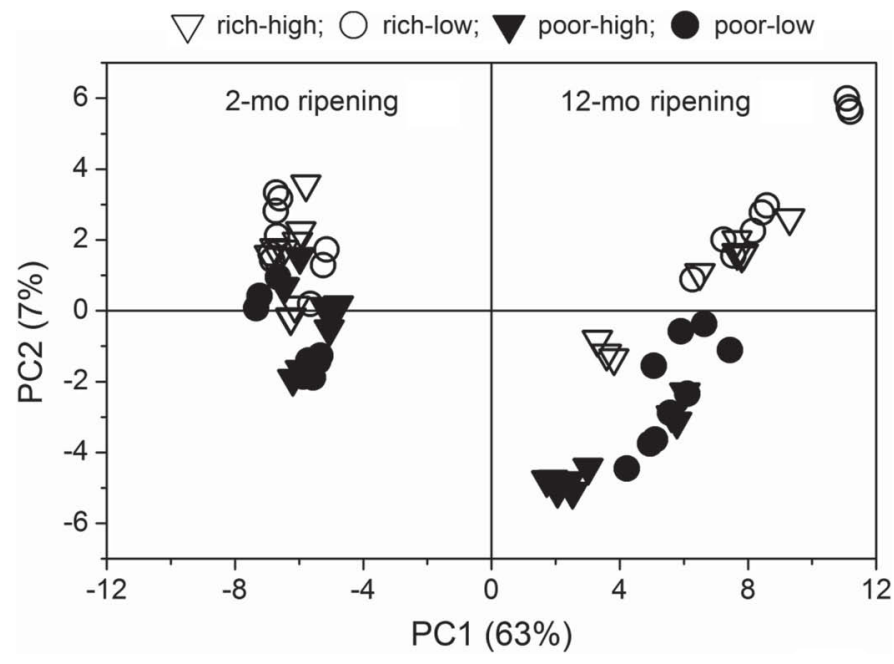

Figure 1. Plot of the first 2 scores of the principal component (PC) analysis of volatile compounds in experimental cheeses (rich $=$ rich pasture; poor $=$ poor pasture; high $=$ high supplement; low $=$ low supplement) at 2 and 12 mo of ripening accounting for $70 \%$ of explained variance (in parenthesis).

the animals or by the interaction between pasture and supplement.

Figures 3c and 3d report the boxplots of 2 representative compounds related to AA metabolism. Dimethyl sulfide is more abundant in the headspace of cheeses from poor pasture $(P<0.01)$ and low supplement level $(P<0.05)$, as shown in Figure 3c; dimethyl sulfide may originate from methionine degradation (Singh et al., 2003). In Figure 3d, 4-methyl phenol (or p-cresol) is shown to be more abundant in the headspace of cheeses from poor pasture $(P<0.01)$ and low supplement level $(P<0.01)$; this latter compound originates from the metabolism of tyrosine (Singh et al., 2003).

A similar pattern was observed for benzaldehyde (pasture effect $P<0.01$; supplement effect $P<0.01$ ) originating from phenylalanine and tryptophan catabolism (Singh et al., 2003). Although the ripening index (Table 2) is not statistically different between the experimental factors, on average, it was higher for poor than rich pasture and higher for low supplement level when compared with the high level. The changes in indigenous milk microflora caused by the cow feeding environment have been demonstrated previously (Hagi et al., 2010), as well as the effect of the different pastures on the bacterial communities in Alpine raw milks (Poznanski et al., 2004). Thus, the observed differences in Montasio cheeses related to feeding and grazing may be justified by the different bacterial communities that can influence AA catabolism and, hence, cheese ripening rather than availability of precursors (proteolysis).

It is well known that the main changes in the cheese volatile profile due to maturation are related to the

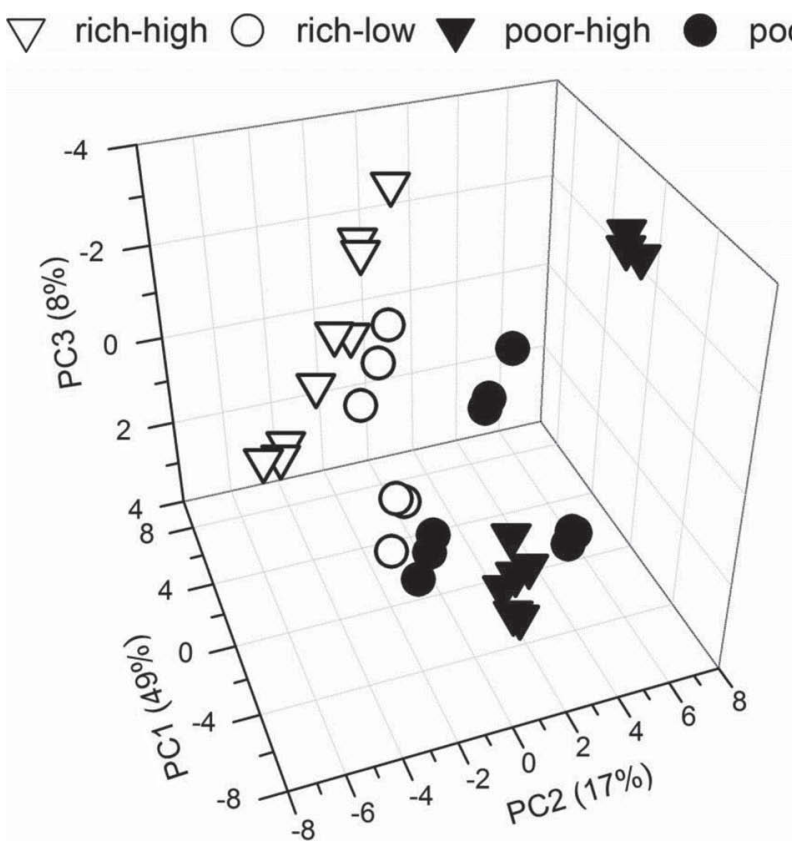

Figure 2. Plot of the first 3 scores of the principal component $(\mathrm{PC})$ analysis of volatile compounds in the 12-mo-ripened Montasio cheeses $($ rich $=$ rich pasture; poor $=$ poor pasture high $=$ high supplement; low $=$ low supplement).

lipolysis and the catabolism of fatty acids (Collins et al., 2003). For example, the amounts of free fatty acids at 12 mo of ripening (Table 3 ) were noticeably higher than those reported at 2 mo of ripening in a previous work (Bovolenta et al., 2014). The other free fatty acids (acetic, butanoic, octanoic, and decanoic acids), with exception of nonanoic acid, show the same pattern as hexanoic acid. Butanoic and hexanoic are the free fatty acids that increase more with the ripening, and this effect has been observed in other ripened hard cheeses, such as Parmigiano Reggiano, Pecorino Romano, Canestrato Pugliese, and Fossa cheese (Fox, 2004).

Another remarkable aspect is the general increase of terpenes, on a DM basis, observed in the cheeses with 12 mo of ripening (Table 3) compared with the cheeses at 2 mo of ripening (Bovolenta et al., 2014). Among terpenes, only 1,8-cineol and (E)-8-hydroxylinalool decreased in concentration below detection threshold. Increase of terpenes during cheese ripening has been already observed by Horne et al. (2005). On the contrary, other authors reported a decrease of such compounds (Barron et al., 2007) or, more commonly, different evolutions for different terpenes (Fernández-García et al., 2008; Delgado et al., 2011; Sulejmani et al., 2014). Belviso et al. (2011) demonstrated that lactic acid bacteria isolated from cheese are able to modify and biosynthesize terpenoids, giving a possible explanation for the differences in terpenes observed during ripening. 


\section{Sensory Panel Evaluation}

The sensory evaluation shows that, between the 2 experimental factors considered (pasture, supplement), only pasture type had significant influence on cheese characteristics (Figure 4a, b). With regard to the visual appearance attributes, the type of pasture had a significant effect on color intensity, eye distribution regularity, humidity, and roughness. Color intensity, highest in rich-pasture cheese, is probably related to the different carotenoids content in cheeses derived from pasture (Noziere et al., 2006). This result is consistent with the colorimetric evaluation that showed a lower lightness for the rich-pasture cheeses; as a consequence, the color of these samples appear more intense than that of the poor-pasture cheeses. Humidity on the surface is probably due to a different melting point maybe linked to the higher content in PUFA of rich-pasture cheese [S. Bovolenta, A. Romanzin, A. Sepulcri (University of Udine), M. Corazzin, E. Piasentier (University of Udine), unpublished data].

Cow, sour milk, and pungent were the odor attributes perceived orthonasally and affected by pasture type. Cow odor was associated, in cheddar cheese, to the presence of $p$-cresol (Suriyaphan et al., 2001). The cheeses produced with milk from poor pasture were scored higher for cow odor, and this result is in agreement with higher amount of $p$-cresol we detected (Figure 3d). Although the amount of $p$-cresol in cheeses produced from milk with a low level of supplementation is similar to that of cheeses produced with milk from poor pasture, the panel did not find differences in cow odor between low and high level of supplementation; this may be due to the interaction with other compounds masking cow odor, such as esters. The differences between cheeses for pungent odor, as well as the slightly acid odor of sour milk, could be caused by a different concentration of free fatty acids, in particular acetic acid (Figure 3a) (a)
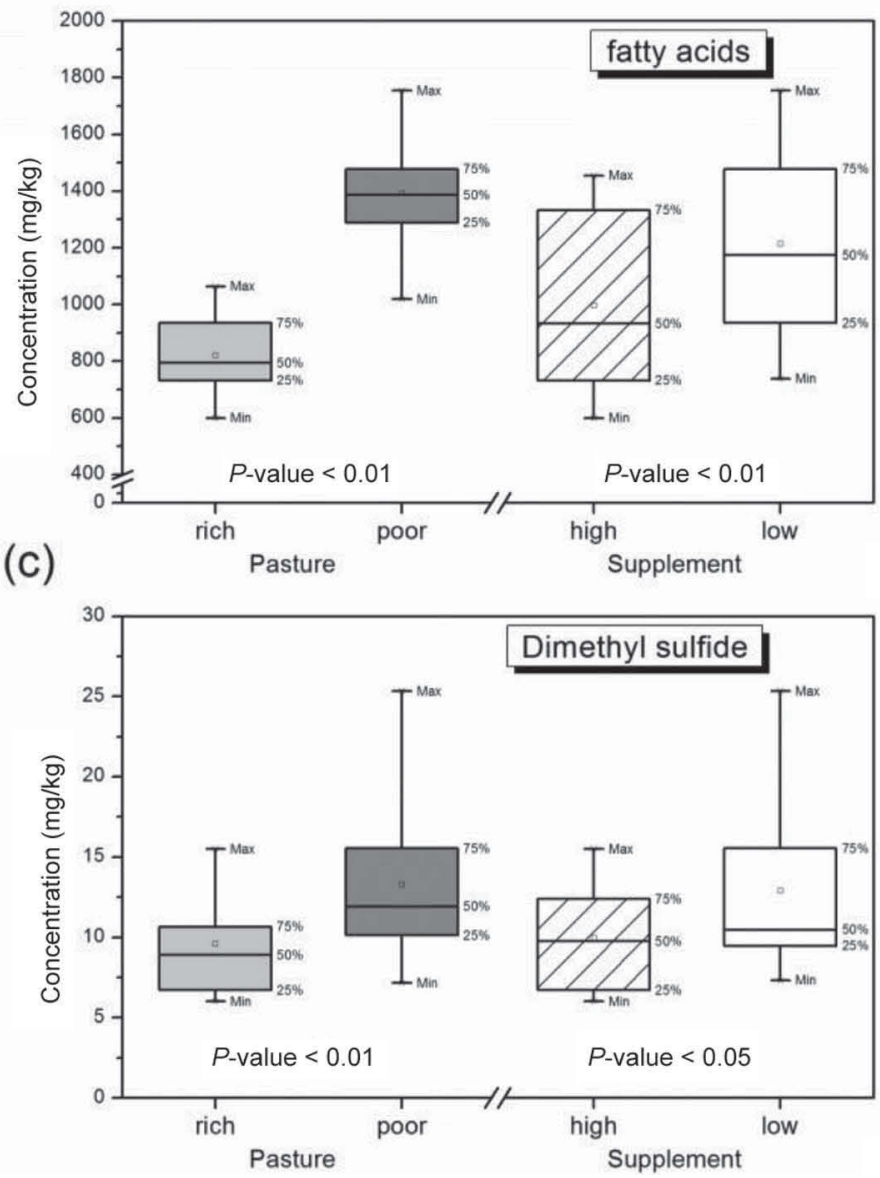

(b)
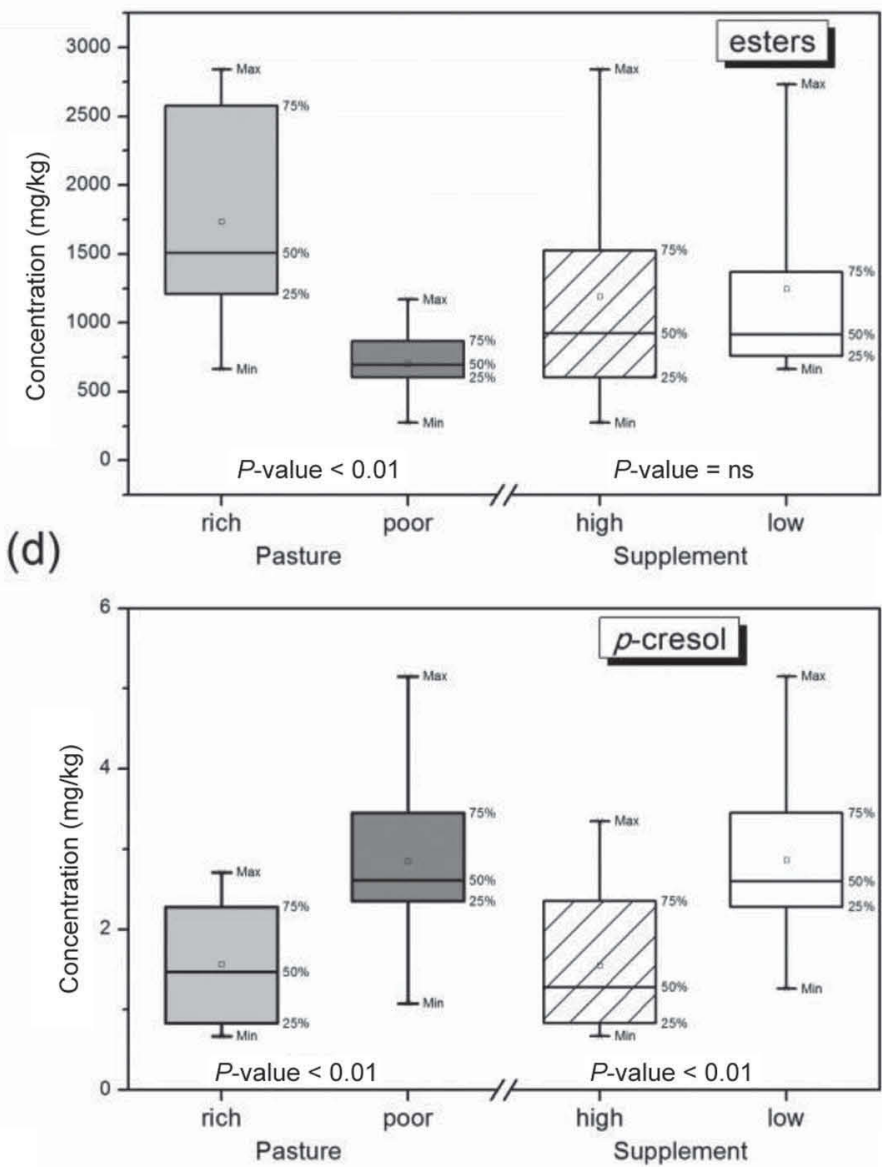

Figure 3. Boxplots of free fatty acids (a), esters (b), dimethyl sulfide (c) and p-cresol (d) present in the headspace of the 12-mo-ripened Montasio cheeses $($ rich $=$ rich pasture; poor $=$ poor pasture; high $=$ high supplement; low = low supplement). Small squares in the boxes represent the mean values whereas whiskers indicate minimum and maximum. 
(a)

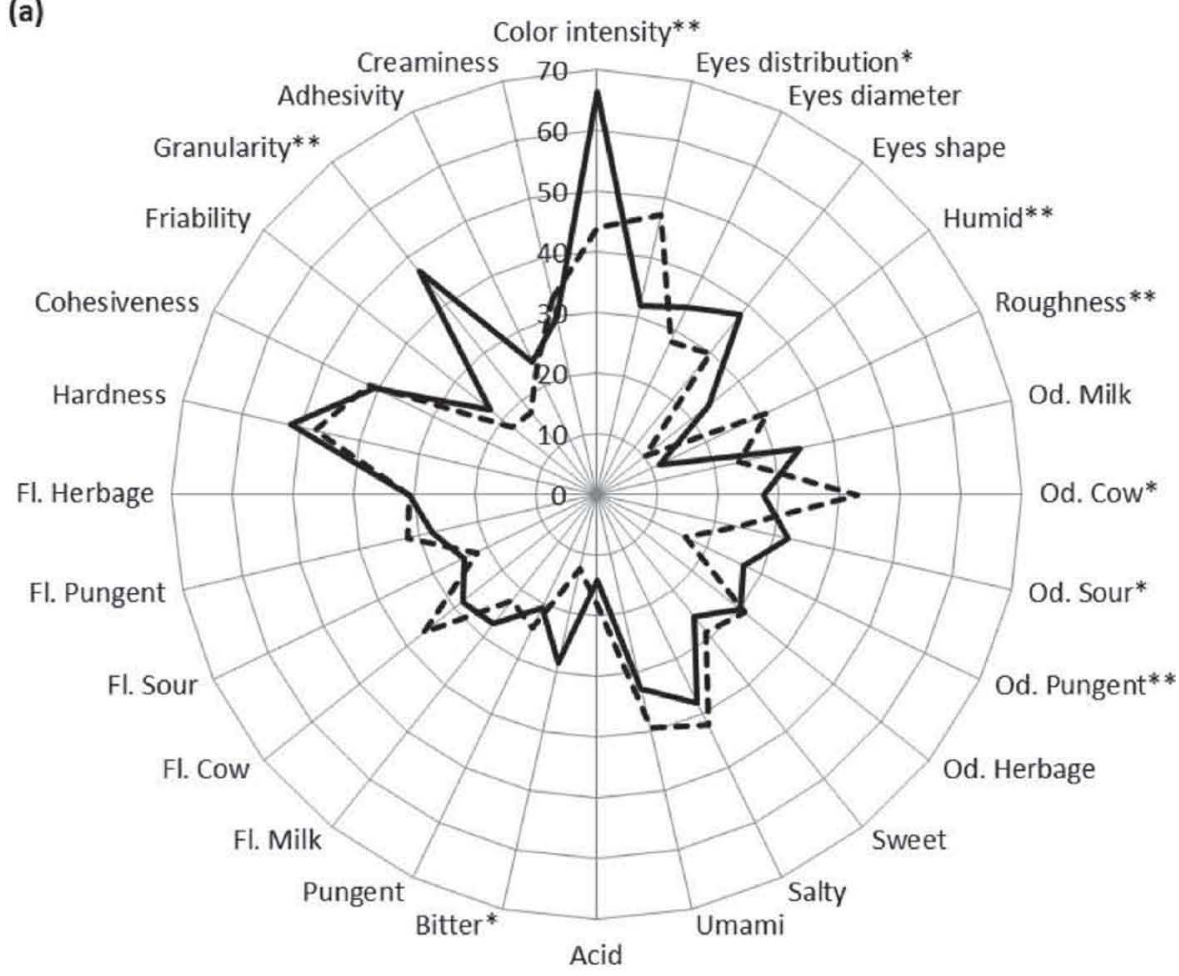

(b)

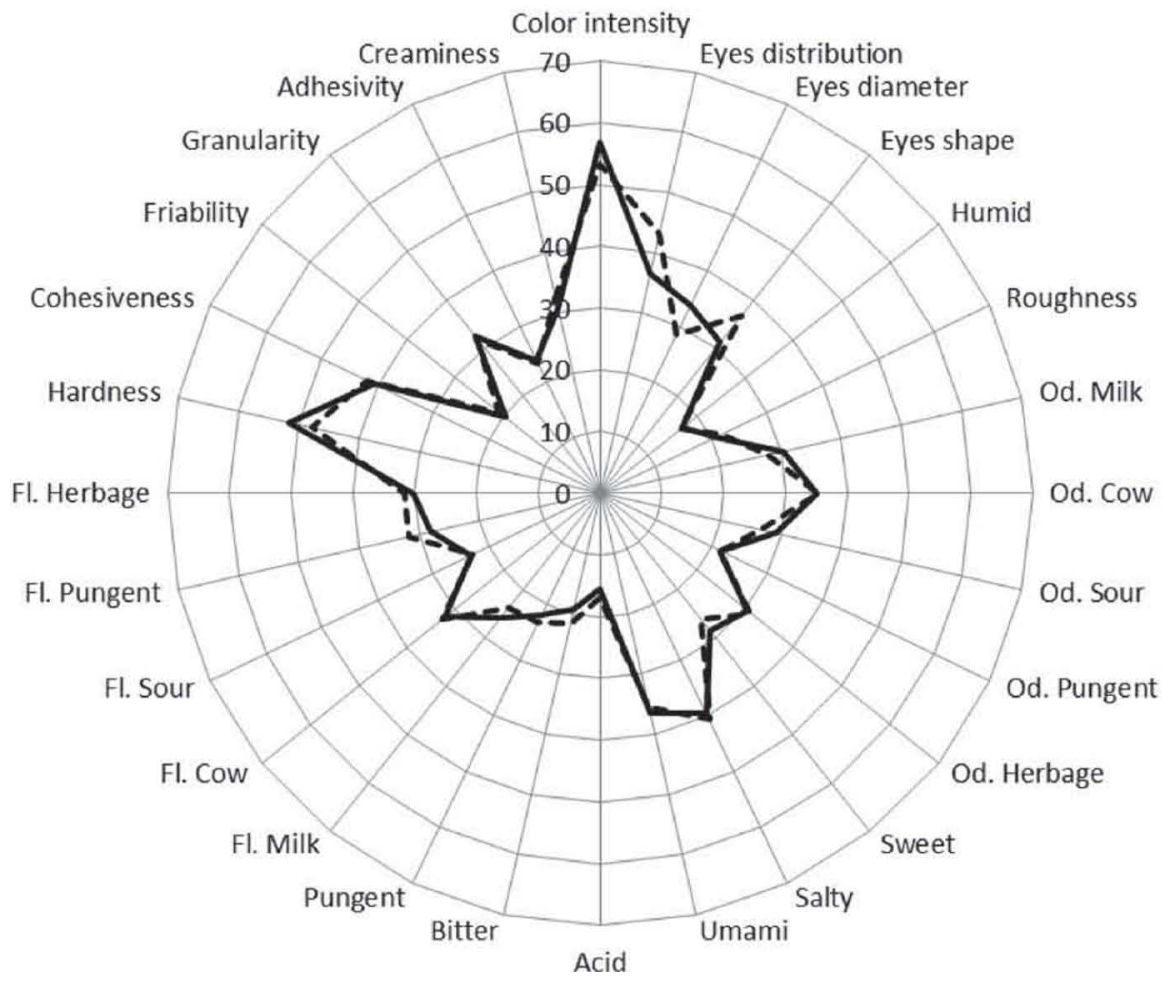

Figure 4. Spider plots depicting descriptive sensory analysis of 12-mo-ripened Montasio cheeses. (a) Solid line $=$ rich pasture; dashed line $=$ poor pasture. (b) Solid line = high supplement level; dashed line = low supplement level. Od = odor; $\mathrm{Fl}=$ flavor. 
and propionic acid (Salvadori del Prato, 2001). This finding may be confirmed by the different eye diameter and regularity, though it was not significant (Figure 4) and usually due to the formation of these compounds.

Among the attributes of taste, bitterness maintained quite constant values in experimental cheeses compared with cheeses at 2 mo of ripening (Bovolenta et al., 2014), although it is known for its tendency to increase during ripening (Sousa et al., 2001). Innocente (2002) detected higher bitterness of Montasio cheeses at 5 mo of ripening; nevertheless, the difference between richand poor-pasture cheeses was significant. This result is probably linked to differences in proteolysis, which is an essential phase in the pathway of flavor development, relying on microbial metabolism of lactic acid bacteria, proteases, and peptidases. Detection of bitterness in cheese was possible when the concentration of bitter peptides exceeded a certain threshold level. The complex mechanism of bitter peptide formation in cheese ripening is difficult to clarify (Lemieux and Simard, 1991, 1992), but the different botanical species in the grass grazed by the cows are a probable cause.

Pasture type did not enhance differences in flavors. On the contrary, granularity during mastication was clearly perceived by the panel in cheeses obtained from rich pasture (Figure 4a). Granularity is one of the typical characteristics of ripened cheeses and is known to be linked to the presence of crystals of tyrosine (Partridge, 2009). Although all texture variables, measured by the texture analyzer, of the cheeses have been influenced by pasture and partly by supplement (Table 2), panelists were not able to perceive these differences in the rheological variables involving the forces applied during chewing (hardness, cohesiveness, friability, adhesiveness, creaminess).

When comparing cheese differences at 2 mo with those at 12 mo of ripening, results were only partly confirmed (Bovolenta et al., 2014). Color intensity, cow smell, and granularity were always higher, but with greater differences in rich than poor pastures. As mentioned, supplement level did not affect sensory evaluation of experimental cheeses nor in 2-mo cheeses (Figure 4b).

\section{CONCLUSIONS}

In this study, the effects of pasture type and of the cow feeding supplementation level on volatile compounds, physicochemical, and sensory characteristics of a 12-mo ripened Montasio cheese were evaluated. Both experimental factors affected VOC profile in cheese whereas chemical composition and physical properties were affected mainly by pasture type. This study demonstrated how a prolonged ripening time modified the volatile compounds potentially related to aromatic properties of Montasio cheese in relation to the feeding differences among cows.

\section{ACKNOWLEDGMENTS}

The authors thank the "Centro di Ricerca e Innovazione Tecnologica in Agricoltura" (CRITA, Udine, Italy) for financial support (funds of Friuli Venezia Giulia Region, L.R. n. 26/2005, art. 18) and the Breeders Association of Friuli Venezia Giulia Region (AAFVG, Codroipo, Italy) for technical collaboration. E. Aprea, E. Betta, and F. Gasperi are supported by the Autonomous Province of Trento (Trento, Italy; AP 2011/2013). The authors thank anonymous reviewers for their insightful and constructive suggestions.

\section{REFERENCES}

AOAC International. 2000. Official Methods of Analysis.. 17th ed. AOAC International, Arlington, VA.

Barham, E. 2003. Translating terroir: The global challenge of France AOC labeling. J. Rural Stud. 19:127-138.

Barron, L. J. R.. Y. Redondo, M. Aramburu, P. Gil, F. J. Pérez-Elortondo, M. Albisu, A. I. Nájera, M. de Renobales, and E. Fernández-García. 2007. Volatile composition and sensory properties of industrially produced Idiazabal cheese. Int. Dairy J. 17:1401-1414.

Belviso, S., M. Giordano, P. Dolci, and G. Zeppa. 2011. Degradation and biosynthesis of terpenoids by lactic acid bacteria isolated from cheese: First evidence. Dairy Sci. Technol. 91:227-236.

Bovolenta, S., M. Corazzin, E. Saccà, F. Gasperi, F. Biasioli, and W. Ventura. 2009. Performance and cheese quality of Brown cows grazing on mountain pasture fed two different levels of supplementation. Livest. Sci. 124:58-65.

Bovolenta, S., A. Romanzin, M. Corazzin, M. Spanghero, E. Aprea, F. Gasperi, and E. Piasentier. 2014. Volatile compounds and sensory properties of Montasio cheese made from the milk of Simmental cows grazing on alpine pastures. J. Dairy Sci. 97:7373-7385.

Bovolenta, S., E. Saccà, M. Corazzin, F. Gasperi, F. Biasioli, and W. Ventura. 2008. Effects of stocking density and supplement level on milk production and cheese characteristics in Brown cows grazing on mountain pasture. J. Dairy Res. 75:357-364.

Bovolenta, S., E. Saccà, M. Corti, and D. Villa. 2005. Effect of supplement level on herbage intake and feeding behaviour of Italian Brown cows grazing on Alpine pasture. Ital. J. Anim. Sci. 4:197-199.

Buchin, S., B. Martin, D. Dupont, A. Bornard, and C. Achilleos. 1999. Influence of the composition of Alpine highland pasture on the chemical, rheological and sensory properties of cheese. J. Dairy Res. 66:579-588.

Collins, Y. F., P. L. H. McSweeney, and M. G. Wilkinson. 2003. Lipolysis and free fatty acid catabolism in cheese: A review of current knowledge. Int. Dairy J. 13:841-866.

Coulon, J. B., A. Delacroix-Buchet, B. Martin, and A. Pirisi. 2004. Relationships between ruminant management and sensory characteristics of cheeses: A review. Lait 84:221-241.

Curioni, P. M. G., and J. O. Bosset. 2002. Key odorants in various cheese types as determined by gas chromatography-olfactometry. Int. Dairy J. 12:959-984.

Delgado, F. J., J. González-Crespo, R. Cava, and R. Ramírez. 2011. Formation of the aroma of a raw goat milk cheese during maturation analysed by SPME-GC-MS. Food Chem. 129:1156-1163. 
Drake, M. A. 2007. Invited review: Sensory analysis of dairy foods. J. Dairy Sci. 90:4925-4937.

Dunn, O. J. 1961. Multiple comparisons among means. J. Am. Stat. Assoc. 56:52-64.

Fernández-García, E., M. Imhof, H. Schlichtherle-Cerny, J. O. Bosset, and M. Nuñez. 2008. Terpenoids and benzenoids in La Serena cheese made at different seasons of the year with a Cynara cardunculus extract as coagulant. Int. Dairy J. 18:147-157.

Fox, P. F. 2004. Cheese: Chemistry, Physics, and Microbiology. Elsevier, Amsterdam, the Netherlands.

Gunasekaran, S., and M. M. Ak. 2003. Cheese Rheology and Texture. CRC Press, Boca Raton, FL.

Hagi, T., M. Kobayashi, and M. Nomura. 2010. Molecular-based analysis of changes in indigenous milk microflora during the grazing period. Biosci. Biotechnol. Biochem. 74:484-487.

Horne, J., S. Carpino, L. Tuminello, T. Rapisarda, L. Corallo, and G. Licitra. 2005. Differences in volatiles, and chemical, microbial and sensory characteristics between artisanal and industrial Piacentinu Ennese cheeses. Int. Dairy J. 15:605-617.

Innocente, N. 2002. Sensorial profiles of Montasio cheese at different levels of ripening. Sci. Tecn. Latt. Cas. 53:173-187.

Jenkins, T. C., and M. A. McGuire. 2006. Major advances in nutrition: Impact on milk composition. J. Dairy Sci. 89:1302-1310.

Lemieux, L., and R. E. Simard. 1991. Bitter flavour in dairy products. I. A review of the factors likely to influence its development, mainly in cheese manufacture. Lait 71:599-636.

Lemieux, L., and R. E. Simard. 1992. Bitter flavour in dairy products, II. A review of bitter peptides from caseins: their formation, isolation and identification, structure masking and inhibition. Lait $72: 335-382$.

Marchesini, G., S. Balzan, S. Segato, E. Novelli, and I. Andrighetto, 2009. Colour traits in the evaluation of the ripening period of Asiago cheese. Ital. J. Anim. Sci. 8(S2):411-413.

Martin, B., I. Verdier-Metz, S. Buchin, C. Hurtaud, and J. B. Coulon. 2005. How do the nature of forages and pasture diversity influence the sensory quality of dairy livestock products? Anim. Sci. $81: 205-212$.

McSweeney, P. L. H. 2004. Biochemistry of cheese ripening. Int. J. Dairy Technol. 57:127-144.

Meilgaard, M. C., V. G. Civile, and B. T. Carr. 2007. Sensory Evaluation Techniques. 4th ed. CRC Press, Boca Raton, FL.

Montel, M. C., S. Buchin, A. Mallet, C. Delbes-Paus, D. A. Vuitton, N. Desmasures, and F. Berthier. 2014. Traditional cheeses: Rich and diverse microbiota with associated benefits. Int. J. Food Microbiol. 177:136-154.
Noni, I. D., and G. Battelli. 2008. Terpenes and fatty acid profiles of milk fat and "Bitto" cheese as affected by transhumance of cows on different mountain pastures. Food Chem. 109:299-309.

Noziere, P., B. Graulet, A. Lucas, B. Martin, P. Grolier, and M. Doreau. 2006. Carotenoids for ruminants: From forages to dairy products. Anim. Feed Sci. Technol. 131:418-450.

Partridge, J. A. 2009. Cheddar and Cheddar type cheese. Pages 225270 in The Sensory Evaluation of Dairy Products. S. Clark, M. Costello, M. A. Drake, and F. Bodyfelt, ed. Springer Science \& Business Media, New York, NY.

Poznanski, E., A. Cavazza, F. Cappa, and P. S. Cocconcelli. 2004. Indigenous raw milk microbiota influences the bacterial development in traditional cheese from an alpine natural park. Int. J. Food Microbiol. 92:141-151.

Revello Chion, A., E. Tabacco, D. Giaccone, P. G. Peiretti, G. Battelli, and G. Borreani. 2010. Variation of fatty acid and terpene profiles in mountain milk and "Toma piemontese" cheese as affected by diet composition in different seasons. Food Chem. 121:393-399.

Romanzin, A., M. Corazzin, E. Piasentier, and S. Bovolenta. 2013. Effect of rearing system (mountain pasture vs. indoor) of Simmental cows on milk composition and Montasio cheese characteristics. J. Dairy Res. 80:390-399.

Salvadori del Prato, O. 2001. Trattato di Tecnologia Casearia. Calderini Edagricole, Bologna, Italy.

Singh, T. K., M. A. Drake, and K. R. Cadwallader. 2003. Flavor of cheddar cheese: A chemical and sensory perspective. Compr. Rev. Food Sci. Food Saf. 2:166-189.

Sousa, M. J., Y. Ardö, and P. L. H. McSweeney. 2001. Advances in the study of proteolysis during cheese ripening. Int. Dairy J. 11:327345 .

Sulejmani, E. A. A. Hayaloglu, and V. Rafajlovska. 2014. Study of the chemical composition, proteolysis, volatile compounds, and textural properties of industrial and traditional Beaten (Bieno sirenje) ewe milk cheese. J. Dairy Sci. 97:1210-1224.

Suriyaphan, O., M. Drake, X. Q. Chen, and K. R. Cadwallader. 2001 Characteristic aroma components of British farmhouse cheddar cheese. J. Agric. Food Chem. 49:1382-1387.

Thomsen, M., C. Martin, F. Mercier, P. Tournayre, J. L. Berdagué, T. Thomas-Danguin, and E. Guichard. 2012. Investigating semihard cheese aroma: Relationship between sensory profiles and gas chromatography-olfactometry data. Int. Dairy J. 26:41-49.

UNI. 2010. UNI EN ISO 8589: Sensory analysis-General guidance for the design of test rooms. UNI, Milan, Italy. 